\title{
2 Terabit Transmission over Installed SMF with Direct Detection Coherent WDM
}

\author{
Paola Frascella and Andrew D. Ellis \\ Photonics System Group, Tyndall National Institute \\ $\&$ Department of Physics, University College Cork
}

Ireland

\section{Introduction}

The way people communicate has continued to evolve in the last decade; information is becoming more visual and digital. Every message exchanged between people is highly likely to be accompanied by high-definition photos or video and transported over long intercity distances. This is the era of Visual Networking (Cisco white paper, 2011a), where social networking websites dominate the market and image based content is increasingly user-generated using advanced personal mobile devices. In 2010, 14.3 petabytes ( $10^{15}$ bytes) of mobile/wireless traffic were offloaded onto the fixed network each month. Driven in part by the increase in devices and the capabilities of those devices, there will be two networked devices per capita in 2015, up from one networked device per capita in 2010, resulting in a $32 \%$ compound annual growth rate (CAGR) of the total (fixed plus mobile) internet traffic. On a long term scale (e.g. the last ten years), the CAGR has been approximately $19 \%$ and the total number of internet users grew from 361 million in Dec 2000 to 2,095 million in March 2011 (www.internetworldstats.com, 2011). Moreover, as telecom technology is deployed in emerging economic powers including Brazil, India and China and is seen by the World Bank as the key to economic independence in sub-Saharan Africa and other areas of the developing world (Reuters, 2010a and 2010b), the exponential growth of global internet traffic will continue, reaching a capacity of one zettabyte (1021) per month shortly after 2015 (Cisco white paper, 2011b).

The deployed networks mostly use standard single-mode fibres (SMF), which support a single propagating mode, and erbium doped fibre amplifiers (EDFAs) for data transport. The fibre is installed undersea, underground and even sometimes running in the airsuspended from overhead cables. Optical fibre is dominant in submarine, long haul and metropolitan area networks, and is beginning to dominate high-performance access networks. The demand for high-capacity data transmission over the installed fibre networks is evident. Innovative solutions to support the continuing increase in capacity currently falls into two alternative approaches: one focuses on direct physical changes to the network to enable the transport of significantly higher capacities, the second on how to transmit more capacity on the existing deployed networks. The first direction involves the study of new optical fibres for more efficient transport of information (Zhu et al., 2011), and new network architectures, essentially allowing the replacement of electrical switches with optical 
implemented alternatives (Dunne et al., 2009). Such a radical change in the network will be adopted when the proposed upgrade to a new fibre and/or a new architecture will offer the network operator groundbreaking improvements, enabling increases in revenue generation above the upgrade cost. The second approach, a more short-term solution, enables moderate upgrade for an immediate satisfaction of the capacity demand, in contrast to the introduction of novel technologies which often require long terms and high investments. In this chapter we focus on a solution within the second approach, providing increased capacity over existing infrastructure at minimum cost and complexity.

In its original form, Ethernet combines low implementation cost, high reliability and relative simplicity of installation to become the de facto local area network standard. Ethernet has evolved and adapted to meet the increasing bandwidth demands of end-users. The latest variants, 40 and 100 Gigabit Ethernet $(\mathrm{GbE})$ were recently standardised by the IEEE data transport applications over both copper and optical fibre. Other enhancements, such as the support for operations, administration and maintenance (OAM) functionality, have contributed to the emergence of Carrier-Class Ethernet as the dominant transport technology in telecommunication networks. Today it is safe to assume that nearly all internet traffic starts and ends with an Ethernet connection. With zettabyte data volumes the server farms, used to host and distribute Visual Networking services, require low cost ultra high-capacity intra and inter-data centre connections. Indeed recent requests for Terabit Ethernet (Lee, 2011; Lam et al., 2010) have motivated the work that we will present in this chapter.

In parallel, dual polarisation quadrature phase shift keying (DP-QPSK) was developed for telecom applications (ITU-T G.709/Y.1331) for the transport of Ethernet without recourse to inverse multiplexing. The spectral resource (the optical fibre bandwidth) is already highly shared through wavelength division multiplexing (WDM) in current networks, and will need to implement high-spectral efficiency techniques in order to carry Terabit Ethernet data in the future. It is widely accepted that multicarrier systems, such as Coherent WDM (CoWDM) and other variants of optical Orthogonal Frequency Division Multiplexing (OFDM), are strong candidates for Terabit Ethernet (TbE) transmission over metro area networks (10-300 km) (Sanjoh et al., 2002; Ellis \& Gunning, 2005; Lowery et al., 2006; Shieh \& Authaudage, 2006; Djordjevic \& Vasic, 2006; Jansen, 2007; Goldfarb et al., 2007; Chen, H. et al., 2009; Hillerkuss et al., 2011; Zhao \& Ellis, 2010). With these techniques, in order to achieve Tbit/s capacities individual WDM channels are further expanded into bands, each containing many orthogonal subcarriers. Orthogonality opens the possibility to transmit higher capacities with reduced cost per bit, without recourse to disruptive network upgrades. Emerging grid-less reconfigurable add-drop multiplexers (ROADMs) (Poole et al., 2011), which are beginning to dominate the market (www.infonetics.com, 2011), in combination with flexible multicarrier solutions offer high capacities in the Tbit/s region and increase the network efficiency (Thiagarajan et al., 2011; Christodoulopoulos et al., 2011; Takara et al., 2010; Bocoi et al., 2009). For a single carrier m-QAM solution, the required optical signal-to-noise ratio increases more rapidly than the capacity increases. In contrast, multi-carrier solutions, such as all-optical OFDM and CoWDM, do not suffer from this limitation and allow for very flexible and scalable total transmitted capacities.

Multicarrier solutions, which meet growing capacity requirements, must offer compatibility with Ethernet. Moreover cost-effective implementations are essential, especially for short network connections as in financial institutions and data centre providers. CoWDM is a 
promising candidate for future high-speed Ethernet transport. In this Chapter we transmit Ethernet packets and implement forward error correction (FEC), showing how this determines the system performance. We identified critical clock stability issues unique to multicarrier systems (Frascella et al., 2010b) and demonstrated the impact on the system design of the more stringent BER of an Ethernet client(Frascella et al., 2010a). In segments of the network where high capacity is needed at the lowest cost, direct detection could be used to avoid the cost, complexity and power consumption of digital coherent receivers. In this chapter, we consider the field transmission of a $2 \mathrm{Tbit} / \mathrm{s}$ multibanded direct detection CoWDM signal over installed SMF, first using EDFA amplification only (Frascella et al., 2010c), and then use Raman amplification to enhance the potential reach (Frascella et al., 2011). Mixed Ethernet (with FEC) and PRBS payloads are used to study both the Ethernet transmission and the performances against fibre impairments of the optical multiplexing format. Fourtynine subcarriers were measured with pre-FEC bit error ratio (BER) performance lower than $10^{-5}$ and post-FEC frame-loss ratio (FLR) below 10-9 for Ethernet transmission over unrepeatered $124 \mathrm{~km}$ of SMF. Outage probability due to polarisation mode dispersion (PMD) is estimated from BER measurements extended over several hours, showing the robustness of CoWDM format. The reach of direct detected 40 Gbaud Terabit capacities is predicted for single-mode fibre based systems as a function of the amplifier spacing, suggesting that CoWDM is suitable for Terabit Ethernet transport over metropolitan links, reaching 1,400 $\mathrm{km}$ at spacing of $80 \mathrm{~km}$ and up to $130 \mathrm{~km}$ unrepeatered transmission.

\section{High-capacity transmission over installed SMF}

In laboratories, the total capacity and the spectral efficiency have drastically grown thanks to the introduction of higher modulation formats and digital coherent detection. In March 2011, records were achieved of $101 \mathrm{Tbit} / \mathrm{s}$ and $11 \mathrm{bit} / \mathrm{s} / \mathrm{Hz}$ in a single-mode single-core optical fibre using coherent detection by (Qian et al., 2011). However, there are no scientific reports of higher-capacity field results than the $3.2 \mathrm{~Tb} / \mathrm{s}$ demonstrated in early 2001 (Chen D. et al., 2001), which was achieved with 80 standard WDM channels carrying $40 \mathrm{Gbit} / \mathrm{s}$ NRZ-OOK spaced at $100 \mathrm{GHz}$ across the L and C-band with Raman amplification and FEC over 3 spans of $82 \mathrm{~km}$ long SMF. The highest spectral efficiencies with high-capacity are achieved with orthogonal multiplexing, both in laboratory (Qian et al., 2011) and field experiments (Frascella et al., 2010c; Xia et al., 2011), although other techniques (e.g. based on pre-filtering) also allow high spectral efficiencies (Gavioli et al., 2010; Roberts, 2011). Multiband transmission with orthogonal multiplexing over field deployed fibre started in 2010 where $759 \mathrm{Gbit} / \mathrm{s}$ total capacity was achieved with off-line processed coherently detected DP-QPSK-OFDM and information spectral density (ISD) of $2.35 \mathrm{bit} / \mathrm{s} / \mathrm{Hz}$ (assuming the use of $7 \%$ FEC overhead) over a total of $764 \mathrm{~km}$ of SMF (Dischler et al., 2010). $2 \mathrm{~Tb} / \mathrm{s}$ capacity with orthogonal multiplexing was first achieved in 2010 using real time direct detection (Frascella et al., 2010c) and then in 2011 offline coherent detection (Xia et al., 2011). The reach and the ISD (respectively, $0.7 \mathrm{bit} / \mathrm{s} / \mathrm{Hz} / \mathrm{pol}$ and $3 \mathrm{bit} / \mathrm{s} / \mathrm{Hz}$ ) were determined by the repeater spacing and receiver complexity.

\subsection{Coherent WDM (CoWDM)}

Coherent WDM is an all-optical implementation of OFDM where phase control of adjacent subcarriers is exploited to minimise inter-subcarrier crosstalk interference arising from non- 
ideal orthogonally-matched filters (or demultiplexing of orthogonal subcarriers). OFDM itself is a specific implementation of orthogonal systems developed in the 1950s (Mosier \& Clabaugh, 1958) and extensively studied in the 1960s (Deman, 1964; Chang, 1966; Ito \& Yokoyama, 1967; Zimmerman, 1967), where similarly to orthogonality condition kept in the time domain to avoid inter-symbol interference (ISI) there is an orthogonality condition in the frequency domain to avoid inter-channel crosstalk interference (Proakis \& Salehi, 2008). This condition may be expressed as:

$$
\int_{-\infty}^{+\infty} X_{k}(f) X_{j}^{*}(f) d f=\int_{-\infty}^{\text {Th. }} x_{k}(t) x_{j}^{*}(t) d t= \begin{cases}E & k=j \\ 0 & k \neq j\end{cases}
$$

where the first equality is Parseval's theorem, $E=\int_{-\infty}^{+\infty}\left|x_{k}(t)\right|^{2} d t$ is the energy of the signal $x_{k}(t)$ of the k-th channel and $X_{k}(f)$ its spectrum (and Fourier transform). If we consider the signal waveforms only to differ in frequency, then the orthogonality condition in Eq. 1 introduces a condition on the signal spacing. OFDM is a particular case of orthogonal system, where the spacing between frequencies is equal to the symbol rate $(1 / T)$ :

$$
\omega_{k}-\omega_{j}=2 \pi / T
$$

Various flavours of orthogonal systems have been proposed, including half of the symbol rate (Chang, 1970; Rodrigues \& Darwazeh, 2002; Zhao \& Ellis, 2010), or close approximations to Eq. (2) (Yamamoto et al., 2010). Whilst all of these systems satisfy the orthogonality condition and may thus be strictly classified as Orthogonal FDM systems, for the last decade (2002-2011) the terminology "OFDM" has been understood to apply to systems with very low inter-subcarrier crosstalk satisfying Eq. 2, and implemented using Fourier Transforms (Weinstein \& Ebert, 1971).

Orthogonally multiplexed multicarrier systems were first proposed for long-haul optical systems in 2002 (Sanjoh et al., 2002), when OFDM was already standardised for DAB HDTV and UMTS. Later on, different varieties were proposed by (Ellis \& Gunning, 2005; Feced et al., 2005; Lowery et al., 2006; Djordjevic \& Vasic, 2006; Shieh \& Authaudage, 2006), and extensively studied in laboratory experiments (Jansen et al., 2008a, 2008b; Shieh et al., 2008; Yonenaga et al., 2009; Sano et al., 2007, 2009; Chandrasekhar et al., 2009; Liu et al., 2009; Schmogrow et al., 2011).

CoWDM derives from the concept that at high symbol rates the orthogonality condition is only maintained if the optical phases $\left(\phi_{\mathrm{k}, \mathrm{j}}=\mathrm{d} \omega_{\mathrm{k}, \mathrm{j}} / \mathrm{dt}\right)$ of the subcarrier $\mathrm{k}$ and $\mathrm{j}$ are constant, and aligned to ensure that any residual crosstalk is distributed away from the eye crossing. When CoWDM was first simulated (Ellis \& Gunning, 2005), patented (Ellis et al., 2009b) and experimentally verified (Ellis \& Gunning, 2005; Gunning et al. 2005; Healy et al., 2006) it was clear that the phase control of each subcarrier, implemented at the transmitter, could ensure orthogonality (reduced BER penalty) by using commercially available modulators and photodiodes with bandwidths comparable to the symbol-rate, rather than the full system capacity, as required for DSP based OFDM (Lowery, 2010). It has been recently been demonstrated that the advantage of phase control is correlated to the transmitter and receiver structure (Ibrahim et al., 2010). Note that the benefit of phase control is negligible in the case of coherently detected dual quadrature signals (Zhao \& Ellis, 2011) and maximum 
in the case of direct detection of single quadrature signals. A signal-to-residual crosstalk ratio (SXR) for OOK signals has been defined (Ibrahim et al., 2010), as the ratio between the signal power in the absence of crosstalk (which corresponds to the signal power in the ' 1 ' bits) and the crosstalk, i.e. the sum of the crosstalk in ' 1 ' bits and ' 0 ' bits. Taking into account only the crosstalk interference coming from the adjacent subcarriers ( $j+1$ and $j-1)$ and assuming no ISI, the SXR for direct detected OOK signals is:

$$
\begin{aligned}
\operatorname{SXR}_{d d} & =\left|x_{j, j}(0)\right|^{2} /\left\{2 \left[\left|x_{j-1, j}(0)\right|^{2}+\left|x_{j+1, j}(0)\right|^{2}+\left|x_{j-1, j}(0) x_{j, j}(0) \cos \left(\phi_{j}-\phi_{j-1}\right)\right|+\right.\right. \\
& \left.\left.+\left|x_{j+1, j}(0) x_{j, j}(0) \cos \left(\phi_{j}-\phi_{j+1}\right)\right|+2\left|x_{j-1, j}(0) x_{j+1, j}(0) \cos \left(\phi_{j-1}-\phi_{j+1}\right)\right|\right]\right\}
\end{aligned}
$$

where $x_{k, j}(0)$ is the baseband representation at the sampling instant of the signal pulse shape for the k-th subcarrier (corresponding to a frequency spectrum $H_{T x}$ ) after optical filtering, demultiplexing and electrical filtering (all included in the frequency response $H_{R x}$ ) targeted to the subcarrier $\mathrm{j}$ :

$$
x_{k, j}(t)=\frac{1}{2 \pi} \int_{-\infty}^{+\infty} H_{T x}\left(\omega-\omega_{k}+\omega_{j}\right) H_{R x}\left(\omega+\omega_{j}\right) e^{j \omega t} d \omega
$$

The cosine terms represent the phase of the beats between all the three subcarriers $j-1, j$ and $j+1$, which pass through the optical filter. From Eq. (3) is evident that by controlling the phase difference between adjacent subcarriers the crosstalk could be minimised (or equivalently the SXR maximised) by setting the CoWDM phase condition:

$$
\left|\phi_{j}-\phi_{j-1}\right|=\frac{\pi}{2}
$$

CoWDM and in general all-optical OFDM are not only robust against dispersion and nonlinearities (Ellis et al., 2009a; Healy et al., 2006; Hillerkuss et al., 2011; Sano et al., 2007; Frascella et al., 2010b), but also remove speed limitations set by electronics as well as linearity issues introduced during EO/OE conversions (Huang et al., 2009). All-optical OFDM promises to achieve Terabit transport in real time, when compared to DSP-based OFDM (Schmogrow et al., 2011; Xia et al., 2011). The ability to operate using direct detection, and over existing dispersions maps (Ellis et al., 2009a), offers the potential for low-cost non-disruptive upgrades making CoWDM an attractive proposition for cost sensitive applications.

\subsection{Transmission of 2 TbE with EDFA only}

The experimental setup used for the field demonstration of the 2 Tbit/s CoWDM is illustrated in Fig. 1. One $10.7 \mathrm{Gbit} / \mathrm{s}$ pseudo-random binary sequence (PRBS) with a 231-1 pattern length was aggregated with three forward error correction (FEC) encoded 10 Gigabit Ethernet $(10 \mathrm{GbE})$ WAN PHY $(9.953 \mathrm{Gbit} / \mathrm{s})$ streams. The PRBS tributary was synchronised to the FEC encoded Ethernet signal and used to monitor the system performance and identify impairments; it was later on replaced with a fourth Ethernet stream to verify the performance of $2 \mathrm{TbE}$. Fourtynine subcarriers were generated from seven DFB lasers using sine wave driven amplitude modulators (Healy et al., 2007; Frascella et al., 2010b). The 


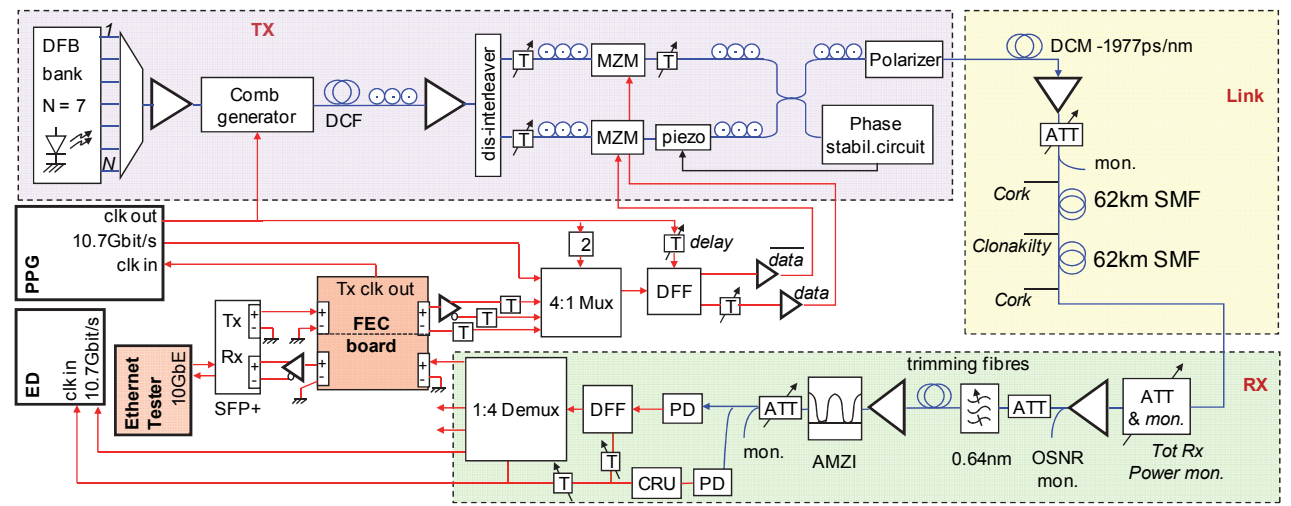

Fig. 1. Experimental setup for $2 \mathrm{Tbit} / \mathrm{s}$ transmission over $124 \mathrm{~km}$ of field-installed SMF (Frascella et al., 2010b). PPG- pulse pattern generator, DFF- D-flip flop, CRU- clock recovery unit; PD- photodiode, ED- error detector, DCM- dispersion compensating fibre.

electrically multiplexed 42.84 Gbaud signals were used to modulate the 49 CoWDM subcarriers with NRZ-OOK, where odd and even channels modulated by data and delayed inverted data respectively. The transmitted spectrum had a total bandwidth of $2.8 \mathrm{THz}$ (guard-bands of $85.67 \mathrm{GHz}$ were introduced to minimize the interference between bands) and transported a total of $2.1 \mathrm{Tbit} / \mathrm{s}$, giving a spectral efficiency of $0.7 \mathrm{bit} / \mathrm{s} / \mathrm{Hz}$ in a single polarization after taking into account $7 \%$ FEC overhead. Inter-subcarrier phases were controlled using an electrically driven piezo fibre-stretcher, where the optimum condition was established by measuring the $42.6 \mathrm{GHz}$ beat frequency between two adjacent subcarriers. The capacity could have been readily doubled using polarisation multiplexing (Cuenot et al., 2007). The fibre link, pre-compensated for chromatic dispersion, used EDFA amplification only. The field-installed SMF was looped-back at Clonakilty to the measurement laboratory in Cork, giving a total span length of $124 \mathrm{~km}$ and an associated loss of $26 \mathrm{~dB}$, which is a challenge in terms of OSNR, as it would be for all unrepeatered links of similar reach. The total signal launch power into the SMF was found to be optimum at $+16.9 \mathrm{dBm}$.

At the receiver, channel selection is performed by a passband filter of $0.64 \mathrm{~nm}$ bandwidth, and a one-tap optical FFT is realised with an asymmetric Mach-Zehnder interferometer (AMZI). After direct detection, the BER and FLR of each optical subcarrier were measured. The BER is shown in Fig. 2, where the best (\#25, $1552.74 \mathrm{~nm})$ and the worst performing (\#48, $1562.77 \mathrm{~nm}$ ) subcarriers are highlighted with different symbols (Fig. 2(a)). At the maximum received power of $-12 \mathrm{dBm}$, the BER of the worst performing subcarrier (\#48) was $1.3 \times 10^{-5}$. The band containing subcarrier \#48 had an OSNR of $30.8 \mathrm{~dB}$ (Fig. 2(b)- the received OSNR is defined per band, as the ratio of the signal power in a band $(2.5 \mathrm{~nm})$ over the noise power in $0.1 \mathrm{~nm}$ bandwidth). The best performing subcarrier (\#25) achieved a BER of $3 \times 10^{-9}$ and an OSNR about $1 \mathrm{~dB}$ higher. Fig. 3(c) shows the received eye-diagrams after optical demultplexing for the best (\#25) and worst (\#48) subcarriers with the crosstalk between adjacent subcarriers remaining minimized at the centre of the eye after transmission over fibre.

We believe that the $6 \mathrm{~dB}$ difference $\left(\right.$ at $\left.10^{-5}\right)$ observed in the required OSNR between the best and worst subcarriers can be attributed to: a) the wavelength sensitivity within the comb 
generation module (see optical spectrum in Fig. 3 (left-axis)); b) the residual gain variation in the optical amplifiers; c) phase errors between adjacent comb lines after transmission (Gunning et al., 2005); and also d) polarisation mode dispersion (Frascella et al., 2010b). An improvement of the flatness of the 49 subcarriers and the introduction of phase control for each individual subcarrier would guarantee an equal OSNR for all subcarriers. This enables the launch power of all subcarriers to be increased to the nonlinear threshold, therefore improving the OSNR and BER of the worst subcarriers. The average receiver sensitivity at a BER of $1 \times 10^{-5}$ across the measured sensitivities for the 49 subcarriers (filled diamonds in Fig. 3) was $\sim-15.5 \mathrm{dBm}$. A BER of $2 \times 10^{-15}$ is required to achieve a FLR of $10^{-12}$ when transmitting an Ethernet frame (Frascella et al., 2010a). FEC boards employing a simple Reed Solomon RS $(255,239)$ code (BER threshold of $1 \times 10^{-4}$, dashed red line \#1 in Fig. 2), as from ITU-T G.975.1 Recommendation, will leave a system margin of $3 \mathrm{~dB}$ received power/OSNR. Enhanced FEC realised with interleaved RS(1023,1007)/BCH $(2047,1952)$ code (BER threshold of $2 \times 10^{-3}$, dashed red line \#2 in Fig. 2) can leave a bigger margin, i.e. $7 \mathrm{~dB}$. Moreover, the removal of additional loss from the system (i.e. variable attenuator and power monitor) could improve this margin even further.

(a)

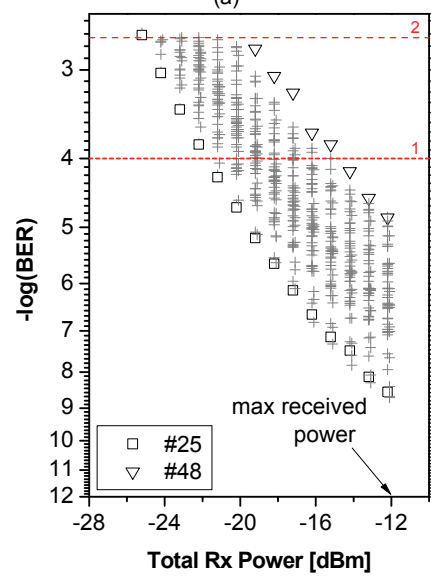

(b)

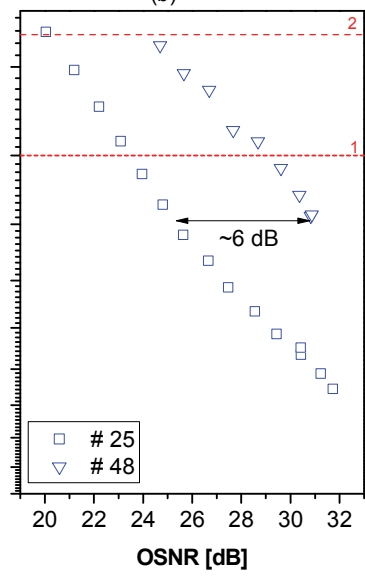

(c)

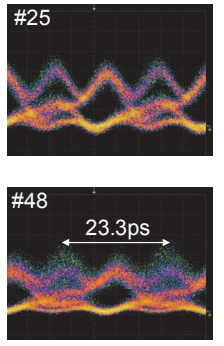

Fig. 2. BER performance after transmission for the best (\#25) and worst (\#48) subcarriers in terms of (a) total received power, and (b) received OSNR. Grey crosses are all the other 47 subcarriers, represented only on the left graph for clarity. The dashed lines in red represent the threshold for (1) the used FEC board and (2) an enhanced FEC threshold of $2 \times 10^{-3}$. (c) Respective eye-diagrams at maximum received power.

Fig. 3 also shows the Ethernet performance of all the 49 subcarriers. No frame-losses were observed for any of the 49 subcarriers for the received total power shown in Fig. 3 (open triangles) when a maximum number of frames $\left(4.3 \times 10^{9}\right)$ allowed in the Ethernet tester for a single run was set, suggesting a frame loss rate of below $2.3 \times 10^{-10}$. When replacing the PRBS tributary with an Ethernet stream, no frame losses were observed for all four FEC-encoded Ethernet WAN PHY streams of the optical subcarrier \#19. This represented the first attempt of such a high Ethernet capacity, $2 \mathrm{TbE}$, transmission over an unrepeatered installed fibre of an inter-city distance. 


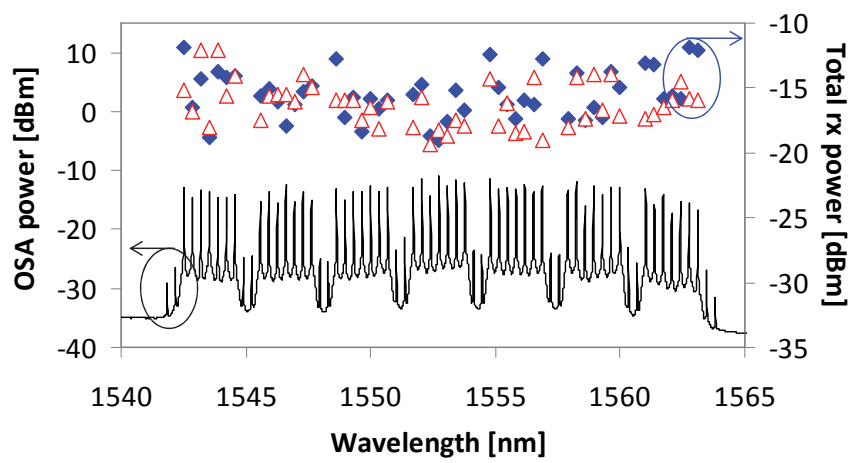

Fig. 3. Left: received optical spectrum after transmission with a resolution bandwidth of 0.02 $\mathrm{nm}$. Right: total received power at BER of $1.0 \times 10^{-5}$ (filled diamonds) and at FLR of $2.3 \times 10^{-10}$ (open triangles).

The BER performance of the PRBS tributary for a random subcarrier (\#19) at the maximum received power $(-12 \mathrm{dBm})$ was monitored over 6 hours to estimate the impact of dynamic effects in the field-installed fibre. The BER variation against time, plotted in Fig. 4, shows fluctuations in the BER of up to two orders of magnitude with a peak BER of $\sim 5 \times 10^{-5}$. We attribute these variations mainly to PMD, but the features from 5 hours onwards might also be due to a memory overload of the algorithm used. The feedback control was implemented on a PC, which stored all the phase error values; therefore at the end of the measurement cycle, the feedback delay was increased due to increasing memory usage. The results in Fig. 4 can also be illustrated as a probability density function (PDF) of $\log (\mathrm{BER})$, as in Fig. 5 (a). In this case, the PDF shows two distinct peaks: the one with the greater amplitude corresponding to a typical Maxwellian distribution associated with PMD, and the other peak can be attributed to either: the proximity of the field-installed fibre cable to a major motor-vehicular transport link, or the response of the phase-stabilization circuit to the intermittent frequency modulation present on the synchronizing clock.

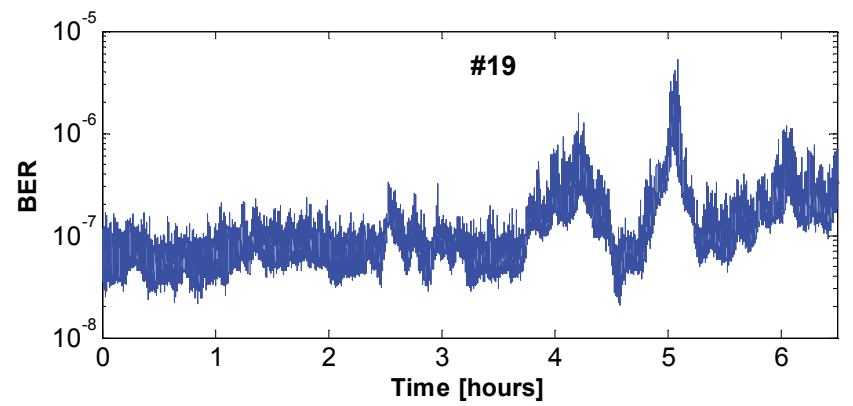

Fig. 4. Long term BER measurement over time for subcarrier \#19. The BER gating window was set to $100 \mathrm{~ms}$.

The outage probability, which is defined as the probability that a system outage occurs, could be estimated to understand how the observed effects degraded the system performance. An outage occurs whenever the BER is greater than 10-12 after FEC decoding. 
(a)

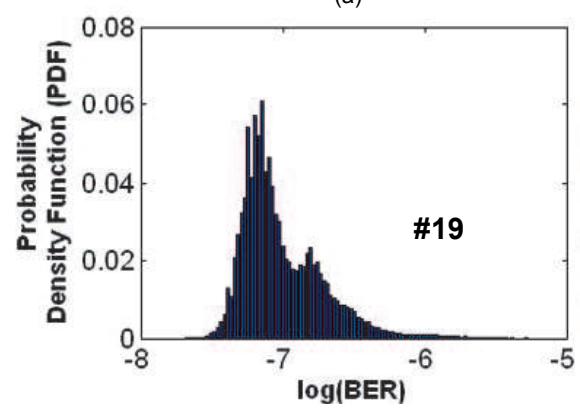

(b)

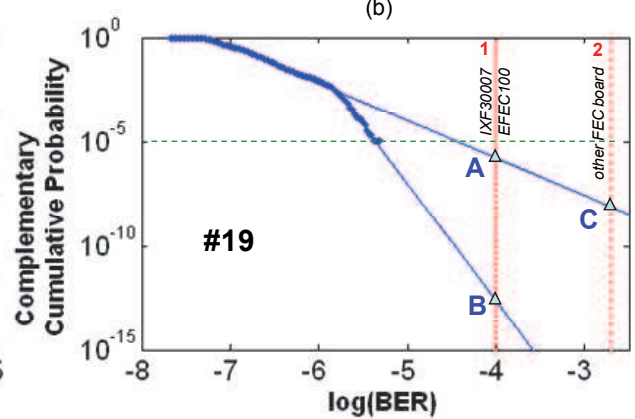

Fig. 5. (a) Probability Density Function (PDF); and (b) complementary cumulative probability calculated from the long term BER measurement relative to an average performance subcarrier (\#19). The blue lines are extrapolating slopes from the data, and dashed red lines represent FEC thresholds as from Fig. 2. The green dashed line represents a desirable outage probability (Kaminow et al., 2008).

From the PDF values in Fig. 5(a), one can calculate the complementary cumulative probability which is plotted in Fig. 5(b) (blue dots). The complementary cumulative probability is defined as the probability that the BER is greater than a certain value (x-axis). The outage probability will then correspond to the intercept between the complementary cumulative probability and the FEC threshold. We consider two extrapolations from the complementary cumulative probability, the first omitting the infrequent high BER events giving an upper bound on the outage probability of $2 \times 10^{-6}$ (point $\mathrm{A}$ in Fig. $5(\mathrm{~b})$ ) and the second including these events, giving a lower bound of $3 \times 10^{-12}$ (point B). Consequently, at full received power, this particular subcarrier delivered an outage probability below the widely used specification of $10^{-5}$ (Kaminow et al., 2008). The outage probability could be substantially improved if an enhanced FEC board, represented as a dashed red line \#2 in Fig. 5(b), were used, which would allow outage probabilities below $8 \times 10^{-9}$ (point C).

\subsection{Hybrid EDFA/Raman amplification}

\subsubsection{Stimulated Raman Scattering}

Raman Scattering is a spontaneous isotropic process where a pump wave is inelastically scattered by the fibre material. The process results in the annihilation of the original photon and the generation of a phonon and a photon at a lower frequency. In optical fibres, only forward (FW) and backward (BW) scattered photons are guided. The vibrational energy level of silica dictates the peak value of the Raman shift, $\Omega_{R}=\omega_{p}-\omega_{s} \sim 13 \mathrm{THz}$ between the pump frequency $\omega_{p}$ and the signal frequency $\omega_{s}$. If a weak probe is injected into the fibre at an appropriate frequency shift from an intense pump, we obtain Stimulated Raman Scattering (SRS) and the maximum SRS gain $g_{R}$ is $0.6 \times 10^{-13} \mathrm{~m} / \mathrm{W}$ at $1.55 \mu \mathrm{m}$ (Stolen et al., 1972; Pizzinat et al., 2003)). The SRS gain has a wide bandwidth (when pump and signal are co-polarised (Headley \& Agrawal, 2005) that exceeds $10 \mathrm{THz}$, making SRS favourable for WDM amplification.

The power exchange between the pump and the signal is governed by the following set of coupled equations, under the approximation of undepleted pumps (Agrawal, 2001): 


$$
\begin{aligned}
& \frac{d I_{s}}{d z}=g_{R} I_{s} I_{p}-\alpha_{s} I_{s} \\
& \frac{d I_{F W}}{d z}=-\alpha_{p} I_{F W} \\
& \frac{d I_{B W}}{d z}=+\alpha_{p} I_{B W}
\end{aligned}
$$

where the intensities of the signal $I_{s}$ and pumps $I_{p}$ (sum of FW and BW), $I_{F W}, I_{B W}$, are all functions of the propagation direction $z$. Also $I_{p}(0)=I_{F W}(0)+I_{B W}(0)$ and $I_{F W}(0)=I_{B W}(\mathrm{~L})=P_{p} / A_{e f f}$ where $P_{p}$ is the nominal power of the pumps in Watts and $A_{\text {eff }}$ is the effective area of the fibre. $\mathrm{a}_{p}\left(=0.069 \mathrm{~km}^{-1}\right.$ for 1427 and $\left.1455 \mu \mathrm{m}\right)$ and $\mathrm{\alpha}_{s}\left(=0.046 \mathrm{~km}^{-1}\right)$ are the attenuation coefficients at the pump and signal wavelength respectively. Solutions of Eq. (6) are:

$$
\begin{aligned}
& I_{F W}(z)=I_{F W}(0) \exp \left(-\alpha_{p} z\right) \\
& I_{B W}(z)=I_{B W}(0) \exp \left(\alpha_{p} z\right)=I_{B W}(L) \exp \left(-\alpha_{p} L\right) \exp \left(\alpha_{p} z\right) \\
& I_{S}(z)=I_{s}(0) \exp \left\{g_{R}\left(\int I_{p}(z) d z\right)-\alpha_{s} z\right\}
\end{aligned}
$$

and

$$
\int I_{p}(z) d z=\frac{I_{F W}(0) \exp \left(-\alpha_{p} z\right)}{-\alpha_{p}}+\frac{I_{B W}(0) \exp \left(\alpha_{p} z\right)}{\alpha_{p}}+c
$$

where $c$ is a constant. We could determine $c$ by setting $z=0$ in Eq. (4):

$$
c=\frac{I_{F W}(0)}{\alpha_{p}}-\frac{I_{B W}(0)}{\alpha_{p}}
$$

The net gain that the signal experiences from one end of the fibre to the other end is given by $G_{n e t}(z)$ :

$$
G_{n e t}(z)=\frac{I_{s}(z)}{I_{s}(0)}=G_{R A}(z) \exp \left(-\alpha_{s} z\right)
$$

where the Raman gain $G_{R A}(z)$ evolves along the propagation direction $z$, giving its main contribution within a pump effective length $L_{e f f}=\left(1-e^{-\alpha_{p} L}\right) / \alpha_{p}$ :

$$
G_{R A}(z)=\exp \left\{g_{R} L_{e f f}\left[I_{F W}(0)+I_{B W}(0) e^{\alpha_{p} z}\right]\right\}
$$

\subsubsection{Noise in Distributed Raman Amplification (DRA)}

A particular advantage of distributed amplification is the reduced effective noise figure coupled with a more uniform power distribution along the fibre, which enables an improved compromise between nonlinearities and noise performances. 
In the case of uni-directional Raman amplification and assuming that the loss coefficients at the pump and signal wavelength are similar $\left(\alpha_{p} \approx \alpha_{s}\right)$, the effective noise figure is given by (Desurvire, 2002):

$$
N F_{R A}=1+2 n_{e q}
$$

where the equivalent input noise factor (Desurvire, 1986 \& 2002; Walker et al., 1991; Kikuchi, 1990), $n_{e q}$, which could be interpreted as the equivalent number of photons per mode at the amplifier input, is given by

$$
\begin{aligned}
& n_{e q}^{F W}=\frac{a_{0}}{\alpha_{s}} \exp \left(-\frac{a_{0}}{\alpha_{s}}\right)\left\{E i\left(\frac{a_{0}}{\alpha_{s}}\right)-E i\left[\frac{a_{0}}{\alpha_{s}} \exp \left(-\alpha_{s} L\right)\right]\right\} \\
& n_{e q}^{B W}=1-\frac{1}{G_{n e t}}+\frac{\alpha_{s}}{a_{0}}\left\{\exp \left(\alpha_{s} L\right)-\frac{1}{G_{n e t}}\right\}
\end{aligned}
$$

where $E i(x)$ is the exponential integral function (Abramovitz \& Stegun, 1972), $a_{0}=\left(\ln G_{n e t}+\alpha_{s} L\right) / L_{e f f}=\ln G_{R A} / L_{\text {eff }}$ is the SRS gain coefficient and $G_{B W}$ is the net gain due to BW pumping only.

When BW pumping is the main source of gain, but bidirectional pumping is also employed, we could express the equivalent noise figure for the Raman amplifier as (Bromage et al., 2004) in Eq. (14) where $G_{F W}$ is the increase in optical signal power when FW pumps are switched on:

$$
N F_{R A}=\frac{N F_{B W}}{G_{F W}}
$$

\subsubsection{Double Rayleigh Backscattering (DRB)}

Rayleigh backscattering (RB) is light scattered backwards to the direction of propagation by material density imperfections occurring in the fibre induced during manufacture. The backscattered intensity increases with fibre length; in SMF (Rayleigh coefficient $R_{s} \sim 6.164 \times 10^{-5}$ $\mathrm{km}^{-1}$ ) it reaches a constant value of $32 \mathrm{~dB}$ below the signal power after approximately $20 \mathrm{~km}$.

The backscattered light may itself be backscattered through the Rayleigh backscattering process, resulting in a doubly backscattered signal. In a conventional fibre without distributed amplification, this process has negligible impact on the system performance, however if the system contains bidirectional gain this effect could significantly degrade the equivalent noise figure of the system. This is particularly the case in the presence of Raman gain which provides distributed gain along the fibre length, but may also be observed in systems employing bi-directional lumped amplifiers. Within a Raman amplified fibre, the DRB signal is given by (Nissov, 1999):

$$
P_{D R B}(z)=P_{S}(z) R_{s}^{2} \int_{0}^{z} \frac{1}{G_{\text {net }}^{2}(x)} \int_{x}^{L} G_{\text {net }}^{2}(y) d y d x
$$

The total equivalent noise figure of a distributed Raman amplifier (DRA), taking into account of amplified spontaneous emission (ASE) and DRB, could be then expressed as (Essiambre et al., 2002): 


$$
N F_{D R A}=N F_{R A}+\frac{1}{G_{n e t}} \frac{\frac{5}{9} P_{D R B}}{h v \sqrt{\Delta v_{e l}^{2}+\frac{\Delta v_{o p t}^{2}}{2}}}
$$

where $5 / 9 P_{D R B}$ is the DRB power copolarised with the signal, $\Delta \mathrm{v}_{\text {opt }}$ and $\Delta \mathrm{v}_{\text {el }}$ are respectively the equivalent double-side bandwidth of the optical signal and the electrical filter at the receiver.

\subsubsection{Impact of cross phase modulation}

Raman amplification can enhance the performances of the CoWDM system in terms of required OSNR and delivered BER (or $Q$ factor). However, the optimization of a DRA system is complex because the distribution of the gain along the transmission fibre improves the OSNR by keeping the signal power from falling to very low levels (low noise figure), but simultaneously increases the signal distortions that result from Kerr and other signal nonlinearities (higher nonlinear phase shift and effective length). Fig. 6 illustrates our experimental setup, which transmits 2 Tbit/s NRZ-OOK CoWDM with PRBS $2^{31}-1$ over the $124 \mathrm{~km}$ installed fibre link with distributed amplification. The hybrid EDFA/Raman system consisted of three units: EDFA \#1 in Fig. 6, FW and BW Raman pumping units. At the output of the transmitter (point A in Fig. 6) the OSNRs (measured per CoWDM band, as the ratio between the signal power in $2.5 \mathrm{~nm}$ and the noise power in $0.1 \mathrm{~nm}$ ) were between 38 and $39 \mathrm{~dB}$, which dropped to below $37 \mathrm{~dB}$ at the output of EDFA\#1. The first stage EDFA also included optical supervisory channel equipment in order to ensure the integrity of the installed link.

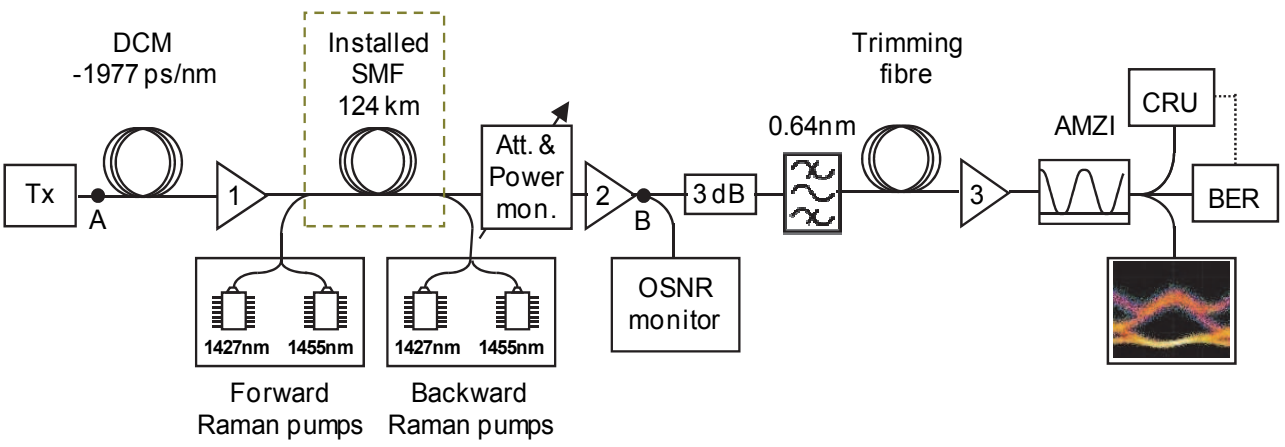

Fig. 6. Experimental setup for hybrid Raman/EDFA transmission over $124 \mathrm{~km}$ installedSMF of 2 Tbit/s OOK CoWDM.

Conventionally, the equivalent noise figure $\mathrm{NF}_{\mathrm{AB}}$ between the points $\mathrm{A}$ and $\mathrm{B}$ in Fig. 6 is defined as:

$$
N F_{A B}=\frac{N F_{1}}{e^{-\alpha_{D C M} L_{D C M}}}+\frac{N F_{D R A}-1}{e^{-\alpha_{D C M} L_{D C M}} G_{E 1}}+\frac{N F_{2}-1}{e^{-\alpha_{D C M} L_{D C M}} G_{E 1} G_{n e t}}
$$


where $N F_{1}$ and $G_{E 1}$ are noise figure and gain of EDFA \#1,NF 2 is the second EDFA's noise figure, $a_{D C M}$ and $L_{D C M}$ are loss coefficient and length of the DCM, $G_{n e t}=G_{\text {net }}(L)$ is the net gain over the SMF as from Eqs. (10) and (11). $N F_{D R A}$ is the equivalent noise figure of the Raman amplifier which takes into account of DRB and ASE as in Eq. (16), and results in a typical output OSNR in the region of around 34dB after Raman amplification.

In order to calculate the evolution of the signal power, the conventional Raman amplification formulas (Eqs. (10) and (11) ) should be modified to take into account the insertion loss of the variable attenuator $\alpha_{A T T}$, insertion losses of the FW pump coupler $\alpha_{x}$, and efficiency parameters of the pump intensities $\eta_{1}, \eta_{2}$ which will also take into account the two wavelengths used within each pump module. We therefore have:

$$
\begin{gathered}
G_{\text {net }}(z)=\alpha_{A T T} e^{-\alpha_{s} z} G_{R A}(z) \\
G_{R A}(z)=\alpha_{x} \exp \left\{g_{R} L_{e f f}\left[\eta_{1} I_{B W}(L) e^{\alpha_{p}(z-L)}+\eta_{2} I_{F W}(0)\right]\right\}
\end{gathered}
$$

Fig. 7 shows the analytically calculated Raman gain (blue solid line), along with experimental measurements (red squares) to confirm the accuracy of the model. This allows the calculation of the signal and DRB powers, assuming zero pump depletion as shown in Fig. 8. Fig. 8(a) shows the case of backwards pumping only with 2 pump wavelengths both at $+27 \mathrm{dBm}$; Fig. $8(\mathrm{~b})$ is the case of bidirectional pumping each with two pump wavelengths at $+27 \mathrm{dBm}$. Even for bidirectional pumping, the DRB power is very low (maximum of -40 $\mathrm{dBm}$ ) and does not degrade the equivalent noise figure significantly. The equivalent link noise figures are $22.7 \mathrm{~dB}$ using backwards pumping only and $11.7 \mathrm{~dB}$ using bidirectional pumping, dominated by ASE generated in the Raman amplifier itself. However, with bidirectional pumping, the signal power excursions are relatively low (increased path averaged power), so for a given launch power, we would anticipate a significant increase in the impact of cross-phase modulation (XPM).

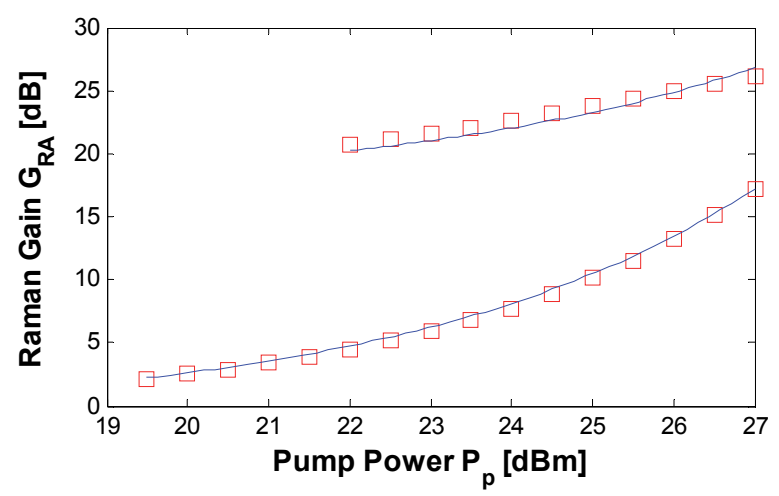

Fig. 7. Raman gain versus pumps' power: experimental data (red squares) and fitting $\left(\eta_{1}=\right.$ $0.68, \eta_{2}=0.36, \mathrm{a}_{x}=1.26$ corresponding to $\sim 1 \mathrm{~dB}$ extra loss, $g_{R}=0.68 \times 10^{-13} \mathrm{~m} / \mathrm{W}$ - blue line). 

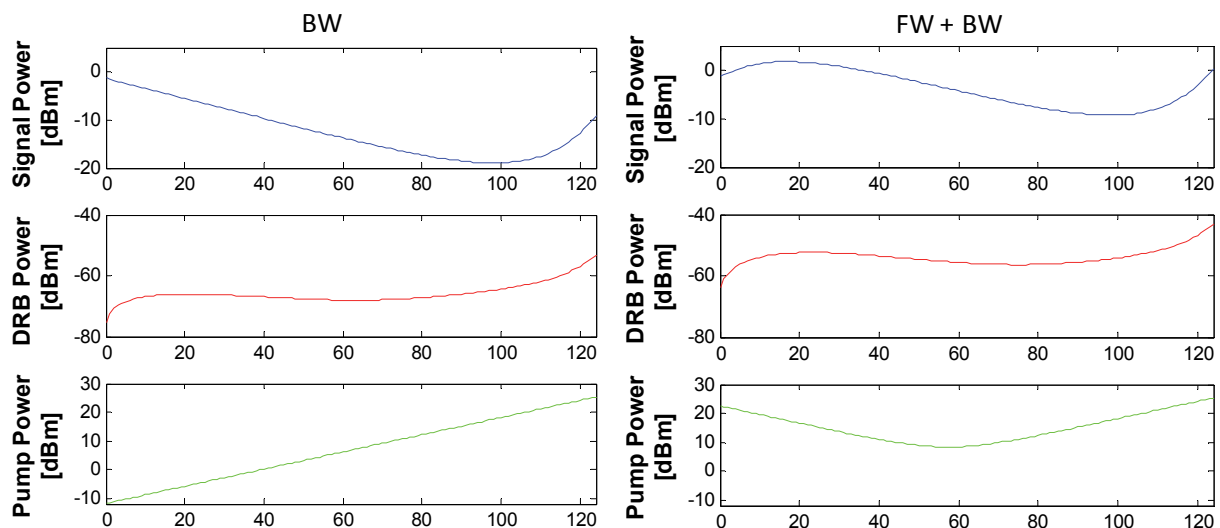

(a)

Distance $z$ along the SMF $[\mathrm{km}]$

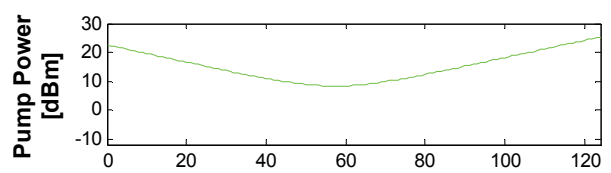

(b)

Distance $z$ along the SMF [km]

Fig. 8. Trend of the signal $\left(P_{s}\right), \mathrm{DRB}\left(P_{D R B}\right)$ and pump $\left(P_{p}\right)$ powers along the SMF.

For a well designed optically pre-amplified receiver, the $Q$ factor for NRZ OOK signal is limited by signal-ASE beat noise and is given by:

$$
\begin{aligned}
& Q=\frac{I_{1}-I_{0}}{\sigma_{1}+\sigma_{0}} \approx \frac{I_{1}}{\sigma_{1}}=\sqrt{S N R} \\
& Q_{d B}=20 \log _{10} Q=10 \log _{10} S N R
\end{aligned}
$$

where $I_{1}$ and $I_{0}$ are the detected photocurrents for the ' 1 ' and ' 0 ' ( $I_{0}=0$ for OOK) and $\sigma_{1}$ and $\sigma_{0}$ are the standard deviations of the noise on the ' 1 ' and ' 0 ' respectively. On a logarithmic scale the $Q$ factor scales linearly with the $S N R$ (and hence with the OSNR) with a slope of 0.5 . This linearly increasing trend is inverted when signal nonlinearities become dominant; as the signal power increases, the $Q$ factor and the BER decrease. Assuming that the system is limited by signal-spontaneous beat noise and XPM, the power dependence of the signal-tonoise ratio may be expressed as (Mitra \& Stark, 2001):

$$
S N R=\frac{P_{c h} e^{-\left(P c h / P_{X P M}\right)^{2}}}{P_{A S E}+P_{c h}\left(1-e^{-\left(P c h / P_{X P M}\right)^{2}}\right)} \approx \frac{P_{c h}\left[1-\left(\frac{P_{c h}}{P_{X P M}}\right)^{2}\right]}{P_{A S E}+\frac{P_{c h}^{3}}{P_{X P M}^{2}}}
$$

where $P_{c h}$ is the power per channel (or subcarrier), $P_{A S E}$ the optical noise (ASE) per polarisation (see Eq. (22)) and $P_{X P M}$ a nonlinear threshold associated with XPM. Near the peak of this function, the exponential terms may be approximated with the first two terms of the Taylor series expansion, giving the right hand form of Eq. (21).The optical noise contains contributions from the transmitter OSNR, the Raman amplifier and the receiver preamplifier, and is given by:

$$
P_{A S E}=\left[n_{e q B W}+n_{s p}\left(\frac{1}{G_{n e t}}-1\right)\right] h v \Delta v_{o p t}+P_{A S E, E 1}
$$


where $\Delta v_{\text {opt }}$ is the receiver optical bandwidth, transparency is assumed (the input power to the Raman amplifier is restored at the output of the receiver preamplifier) and $P_{A S E, E 1}$ is the contribution from the transmitter OSNR. The XPM modelled by (Mitra \& Stark, 2001) for a multi-span system assumes decorrelation in space and time, which corresponds to particular ratios of nonlinear, dispersion and walk of lengths. However, for a single span system, the impact of such decorrelation is reduced, and we could anticipate that the nonlinear intensity would be inversely proportional to the Raman effective length. Taking into account this, we find that a good fit to our experimental data is obtained if we multiply the nonlinear threshold from (Mitra \& Stark, 2001) by the ratio of effective lengths with and without Raman pumping, as following:

$$
P_{X P M}=\sqrt{\frac{B D \Delta \lambda L_{e f f, E D F A}}{2 \gamma^{2} \ln \left(N_{c h} / 2\right) L_{e f f, R}^{2}}}
$$

where $r$ and $D$ are the nonlinear and the chromatic dispersion coefficients of the SMF, $N_{c h}$ is the total subcarrier number, $B$ is the subcarrier bandwidth and $\Delta \lambda$ is the subcarrier spacing. The effective Raman length $L_{e f f, R}$ and the effective EDFA length $L_{e f f, E D F A}$ are:

$$
\begin{aligned}
& L_{e f f, R}=\int_{0}^{L} G_{n e t}(z) d z \\
& L_{e f f, E D F A}=\frac{1-e^{-\alpha_{s} L}}{\alpha_{s}}
\end{aligned}
$$

where $L$ is the SMF span length. From Eq. (21) we observe that the $Q$-factor (or equivalently the SNR) of the system will vary substantially when varying both the Raman gain and the launched power into the optical fibre, because of the trade-off between OSNR (or NF) and nonlinearities. Assuming dominance of XPM, we can predict the $Q$-factor of the system when varying both the Raman gain and the launched power into the optical fibre, as in the contour plot depicted in Fig. 9. An optimum operating area is identified were the $Q$-factor is maximum; the optimum launch power into the SMF with Raman amplification is few dBs lower than the EDFA only system, and it may be varied by around $5 \mathrm{~dB}$ for approximately the same delivered BER or $Q$-factor. An equivalent Raman gain must be provided to counterbalance the lower launch power. Note that for gains below $17.2 \mathrm{~dB}$ only the $\mathrm{BW}$ pumps were used, whilst for higher gains maximum BW pump power was combined with an appropriate level of forward pumping.

\subsubsection{Experimental results}

Experimentally two cross-sections ( $\sigma_{1}$ and $\sigma_{2}$ ) of Fig. 9 were studied. For a fixed Raman gain of $17.2 \mathrm{~dB}$ (BW only), the gain of the first EDFA was varied in order to evaluate the nonlinear power threshold (corresponding to cross section $\sigma_{1}$ in Fig. 9). Fig. 10 shows the $Q-$ factor in $\mathrm{dB}$, calculated directly from the BER measurements for the worst-performing optical subcarrier \#48 (left-axis, blue circles) at the receiver, against the launch power, varied via the gain of the first EDFA. A similar trend was measured on subcarrier \#17; hence negligible variation in the nonlinear performance is expected across the $21 \mathrm{~nm}$ bandwidth. Fig. 10 also shows the OSNR for the 7th band (containing subcarrier \#48) measured at the 


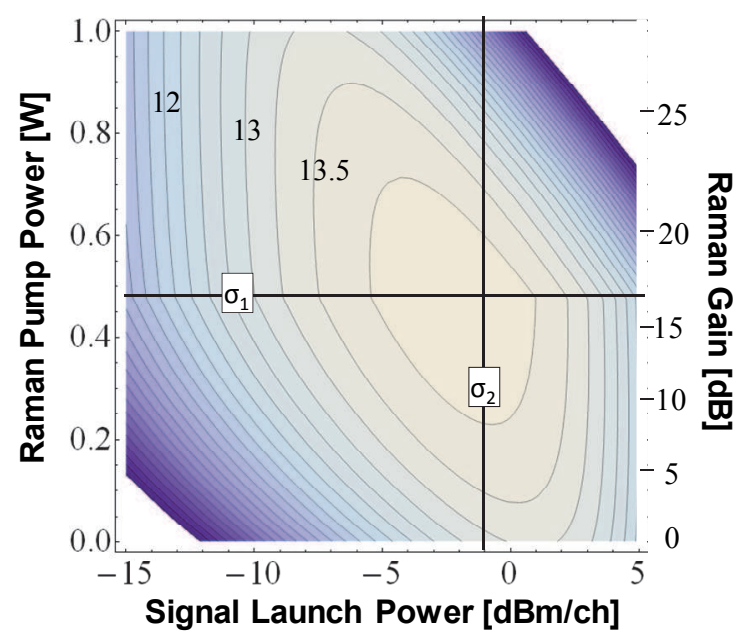

Fig. 9. Predicted $Q$-factor as a function of power per subcarrier and Raman gain, assuming XPM and limitations, $3.4 \mathrm{~dB}$ multiplexing $Q$-penalty and finite transmitter OSNR (see Fig. 10 for details). See text for details of Raman pump conditions. Contour levels are in steps of 0.25 . Operating conditions for BER measurements shown as cross-sections $\sigma_{1}$ and $\sigma_{2}$.

output of the first EDFA (\#1 in Fig. 6) showing the small variation in OSNR, as a result of variations in the amplifier population inversion. At low power levels, the degradation in $Q$-factor (left-axis, blue circles) is caused by a lower OSNR (right-axis, red circles); at high powers, the OSNR increases but the $Q$-factor starts degrading due to nonlinearities. The optimal operating condition was about $-1 \mathrm{dBm}$ per subcarrier launched into the SMF. Fig. 10 also shows the analytical fit for the $Q$-factor, taking into account the transmitter OSNR and a $3.4 \mathrm{~dB}$ multiplexing $Q$-penalty observed for this subcarrier (which could be found in the experimental measurement (Fig. 12)) showing agreement within $0.5 \mathrm{~dB}$ across the entire launch power range studied.

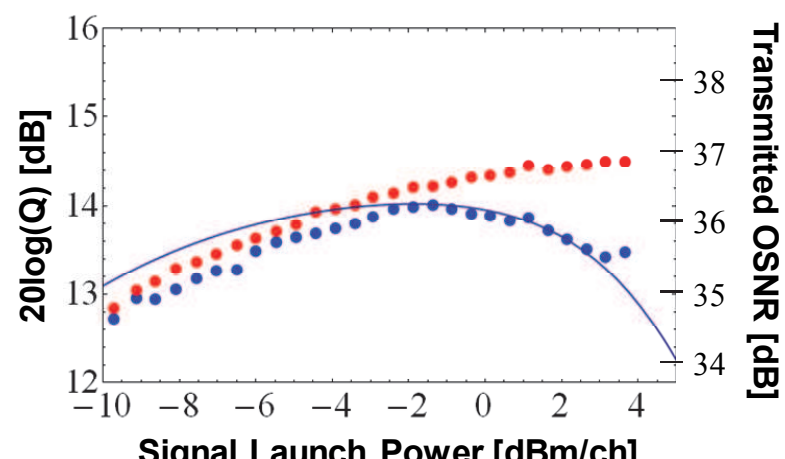

Fig. 10. $Q$-factor calculated from BER measurements (blue circles, left-y axis) for optical subcarrier \#48, and measured OSNR (for the associated band) at the output of the transmitter EDFA (red circles, right-y axis) against power per subcarrier at the input of 124 km installed-SMF. Solid line represents analytically predicted performance (see Fig. 9). 
At the optimum launch power, the Raman gain was increased from $17.2 \mathrm{~dB}$ by increasing the FW pump power or decreased from this level by reducing the BW pump power (crosssection $\sigma_{2}$ in Fig. 9). In Fig. 11 the $Q$-factor (calculated from measured BER for optical subcarrier \#48 (left-axis)) against the on-off Raman gain is plotted as blue circles. The measured OSNR at the output of the receiver preamplifier is also shown on the right-axis. Experimental optimum working conditions were found to be a Raman gain of 17.2 dB (BW Raman only) and launch power of $-1 \mathrm{dBm}$. This agrees well with the analytical predictions (solid lines in Fig. 10 and 11). At this operating point, all 49 subcarriers were characterized in terms of BER performance, and the corresponding $Q$-factors are shown in Fig. 12 (right-y axis) along with the transmitted spectrum, in order to identify the 49 wavelengths. An average $Q$-factor of $15 \mathrm{~dB}$ across the 49 subcarriers was observed after transmission (Frascella et al., 2011), which gave a system margin of $\sim 4 \mathrm{~dB}$ when related to a BER of $2 \times 10^{-3}$ (enhanced FEC threshold) for 2 Tbit/s system based on CoWDM. BW Raman amplification induced a $3 \mathrm{~dB}$ OSNR improvement when compared to an EDFA only amplification system (Frascella et al., 2010b), but at maximum BW Raman gain only a $1.2 \mathrm{~dB}$ improvement in the Q-factor was achieved due to the impact of cross phase modulation.

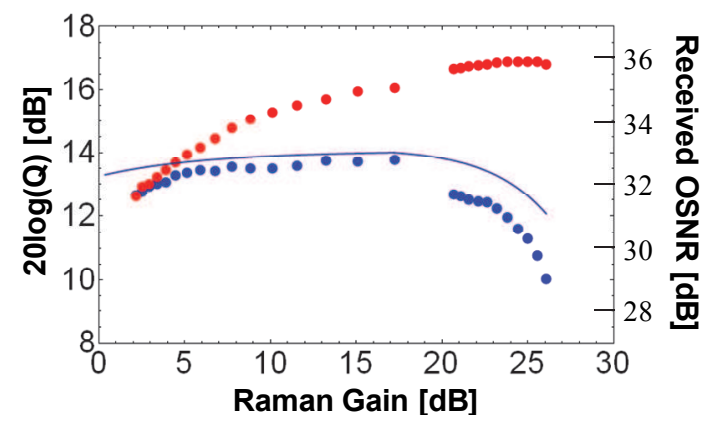

Fig. 11. Q-factor calculated from BER measurements (blue circles, left-y axis) for optical subcarrier \#48, and measured OSNR (for the associated band) at the output of the receiver preamplifier (red circles right-y axis) as a function of Raman gain (below 17dB, backwards pumping only). Solid line represents analytically predicted performance (see figure 9).

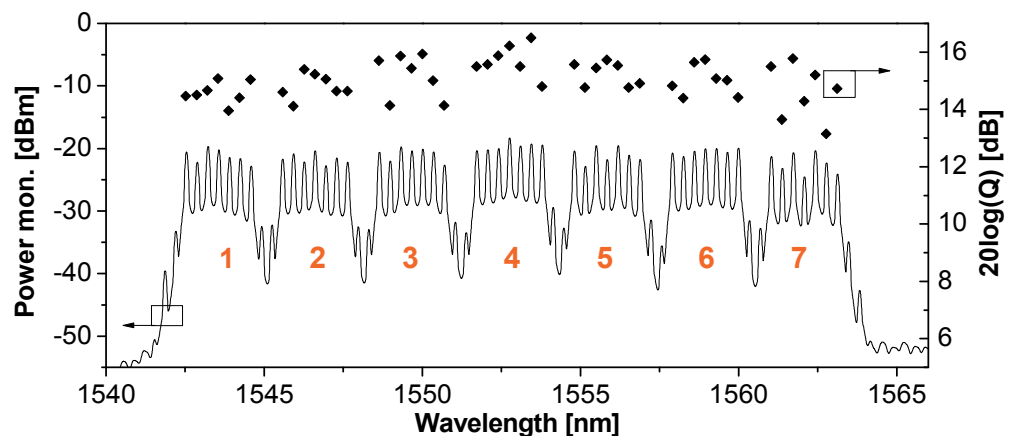

Fig. 12. Spectrum at the transmitter output, with band numeration shown (left-y axis).

Calculated $Q$-factor from BER measurements of all 49 subcarriers with hybrid Raman/EDFA amplification (right y-axis). 


\section{Discussion}

Having established the accuracy of the analytical predictions using both gain measurements and $Q$-factor analysis, Eq. (21) may be used to estimate the maximum reach of a 40 Gbaud direct detected OOK CoWDM system. Further assuming periodic dispersion compensation such that the signal power and the pulse shape at the input of each span is the same, the nonlinear threshold remains as given in Eq. (23), and the optical noise power needs to be multiplied by the number of fibre spans $N_{A}$.
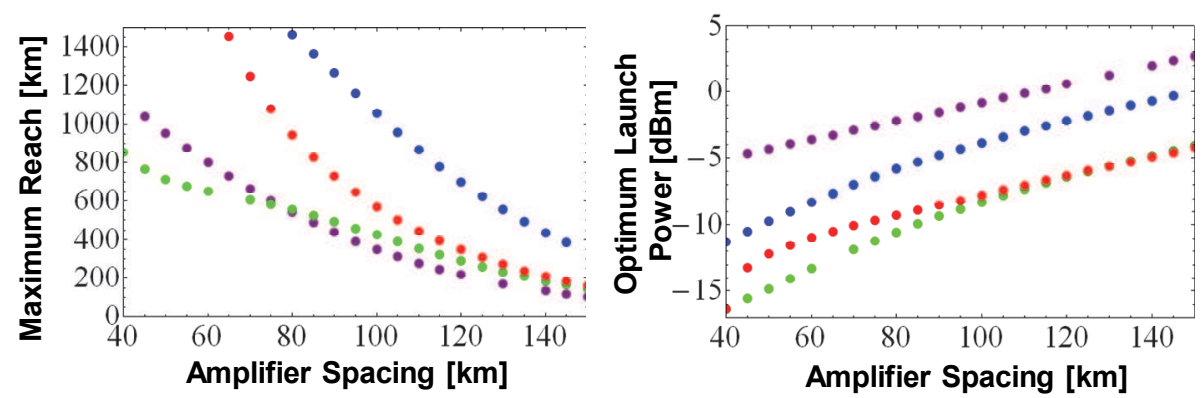

Fig. 13. Reach (left) and optimum per subcarrier launch power (right) of a 40 Gbaud OOK CoWDM system for delivering a BER of $10^{-5}$ (corresponding to frame loss free Ethernet performance) calculated under the experimental conditions ( $3.4 \mathrm{~dB}$ maximum multiplexing penalty and finite transmitter OSNR). Purple, EDFA only; Blue, Backwards pumping; Red forwards pumping; Green, bidirectional pumping. Pump powers at maximum in each case.

This approach may be used to determine the total reach $L_{T}$ dependence on the amplifier spacing $L_{A}$ (implicit in $N_{A}$ ) and the optimum signal launch power $P_{i n}$, as plotted in Fig. 13 for a target SNR of $16.3 \mathrm{~dB}$, corresponding to a worst case BER of $10^{-5}$ (allowing from frame loss free Ethernet performance after FEC) and a $3.4 \mathrm{~dB}$ multiplexing penalty. As expected, the reach is larger for low amplifier spacing, which offers reduced gains and reduced levels of ASE, although this solution tends to result in increased cost due to the increased number of amplifier sites. The EDFA only case offers the lowest reach, whilst the BW Raman amplification alone allows the maximum increase in reach. The forward pumping allows instead for significantly lower optimum signal launch powers (right hand graph in Fig. 13), but the OSNR benefits are reduced by the increased effective length.

At $124 \mathrm{~km}$ spacing, it is confirmed that the best reach is achieved at a launch power close to $-1 \mathrm{dBm}$ in good agreement with the measured nonlinear threshold. Using reduced amplifier spacing of $80 \mathrm{~km}$ or below, the reach is increased to beyond 1,400 km, confirming the suitability of 40 Gbaud direct detected OOK CoWDM system for use in ultra high capacity metro area networks employing dispersion management.

\section{Conclusions}

This chapter demonstrates that direct detection CoWDM with EDFA amplification only is suitable for Terabit Ethernet transport over unrepeatered spans up to $\sim 130 \mathrm{~km}$. Raman amplification would allow for an increased system margin, where necessary. Experimental demonstration showed that one $124 \mathrm{~km}$ span transmission with Raman amplification left a 
$Q$-factor system margin of about $4 \mathrm{~dB}$, which is consistent with theoretical expectations. For a repeatered system employing EDFAs, with $80 \mathrm{~km}$ amplifier spacing the reach of direct detected 40 Gbaud OOK 2 Tbit/s is expected to be $500 \mathrm{~km}$ whilst with Raman amplification, reaches in excess of $1,000 \mathrm{~km}$ are possible for repeater spacing below $100 \mathrm{~km}$ (Healy et al., 2007). Hence orthogonal multiplexing and direct detection constitute a feasible low-cost per bit solution for metropolitan links based on single-mode fibres.

\section{Acknowledgments}

The authors acknowledge F.C.G. Gunning, C. Antony, N. MacSuibhne, S.K. Ibrahim from the Photonics Systems Group of the Tyndall Institute and P. Gunning from BT Innovate and Design for invaluable assistance with the experimental demonstrations; W. McAuliffe and D. Cassidy from BT Ireland for provision of and access to the installed optical fibre; D. Pearce from Ixia Europe for the loan of Ethernet Protocol Test Equipment. This work was supported in part by Science Foundation Ireland (SFI) under grant number 06/IN/I969

\section{References}

Abramovitz, M. \& Stegun, I.A. (1972). Handbook of Mathematical Functions. Dover Publications, New York, 1972, chapters 15 and 22.

Agrawal, G.P. (2001). Nonlinear Fiber Optics. 3rd ed., Academic Press, San Diego, CA, 2001.

Agrawal, G.P., (2002). Fiber-Optic Communication Systems. $3^{\text {rd }}$ edition, Wiley Inter-Science, New York, 2002.

Bocoi, A., Schuster, M., Rambach, F. \& Kiese, M., Bunge, C.-A. \& Spinnler, B. (2009). ReachDependent Capacity in Optical Networks Enabled by OFDM. Proceedings of Optical Fiber Communication (OFC) Conference 2009, OMQ4.

Bromage, J., Bouteiller, J.-C., Thiele, J., Brar, K., Nelson, L.E., Stulz, S., Headley, C., Boncek, R., Kim, J., Klein, A., Baynham, G., Jørgensen, L.V., Grüner-Nielsen, L., Lingle, R.L.Jr. \& DiGiovanni, D.J. (2004). WDM Transmission Over Multiple Long Spans With Bidirectional Raman Pumping. IEEE Journal of Lightwave Technology, Vol.22, No.1, pp.225-232.

Chandrasekhar, S., Liu, X., Zhu, B. \& Peckham, D.W. (2009). Transmission of a 1.2-Tb/s 24Carrier No-Guard-Interval Coherent OFDM Superchannel over 7200-km of UltraLarge-Area Fiber. European Conference on Optical Communications (Sep 2009), PD2.6.

Chang, R. W. (1966). Synthesis of band-limited orthogonal signals for multichannel data transmission. Bell System Technological Journal, Vol. 45, pp. 1775-1796 (Dec. 1966).

Chang, R. (1970). Orthogonal frequency multiplex data transmission system. US Patent 3,488,445, filed Nov 1966, published Jan 1970.

Chen, H., Chen, M. \& Xie, S. (2009). All-optical sampling orthogonal frequency-division multiplexing scheme for high-speed transmission system. IEEE Journal of Lightwave Technology, Vol.27, No.21, pp. 4848-4854.

Chen, D., Wheeler, S., Nguyen, D., Färbert, A., Schöpflin, A., Richter, A., Weiske, C.-J., Kotten, K., Krummrich, P.M., Schex, A. \& Glingener, C. (2001). 3.2 Tb/s field trial $(80 \times 40 \mathrm{~Gb} / \mathrm{s})$ over $3 \times 82 \mathrm{~km}$ SSMF using FEC, Raman and tunable dispersion compensation. Optical Fiber Communication Conference (2001), PD36. 
Christodoulopoulos, K., Tomkos, I. \& Varvarigos, E. (2011). Dynamic Bandwidth Allocation in Flexible OFDM-based Networks. Proceedings of Optical Fiber Communication (OFC) Conference 2011, OTuI5.

Cisco white paper (Feb 2011). Cisco Visual Networking Index: Global Mobile Data Traffic Forecast Update, 2010-2015, available from http:/ / www.cisco.com

Cisco white paper (June 2011). Entering the Zettabyte Era, 2010-2015, available from http://www.cisco.com

Cuenot, B., Gunning, F.C.G., McCarthy, M., Healy, T. \& Ellis, A.D. (2007). 0.6 Tbit/s capacity and $2 \mathrm{bit} / \mathrm{s} / \mathrm{Hz}$ spectral efficiency at $42.6 \mathrm{Gsymbol} / \mathrm{s}$ using a single DFB laser with NRZ coherent WDM and polarization multiplexing. Proceedings of CLEO-Europe (2007), CI8-5-FRI.

Deman, P. (1964). Frequency and Time Allocation Multiplex System. US Patent 3163718, filed Jun 1962, published Dec 1964.

Desurvire, E. (2002). Erbium Doped Fiber Amplifiers. Principles and Applications. John Wiley \& Sons, New Jersey 2002, pp.121-136.

Dischler, R., Klekamp, A., Buchali, F., Idler, W., Lach, E., Schippel, A., Schneiders, M., Vorbeck, S. \& Braun, R.-P. (2010). Transmission of $3 \times 253-G b / s$ OFDMSuperchannels over $764 \mathrm{~km}$ field deployed single mode fibers. Optical Fiber Communication Conference (2010), PDPD2.

Djordjevic, I.B. \& Vasic, B. (2006). Orthogonal Frequency Division Multiplexing for HighSpeed Optical Transmission. Optics Express, Vol.14, pp. 3767-3775, May 1, 2006.

Dunne, J., Farrell, T. \& Shields, J. (2009). Optical Packet Switch and Transport: A New Metro Platform to Reduce Costs and Power by $50 \%$ to $75 \%$ While Simultaneously Increasing Deterministic Performance Levels. International Conference on Tranpsarent Optical Networks (July 2009), Mo.D4.4.

Ellis, A.D. \& Gunning, F.C.G. (2005). Spectral density enhancement using Coherent WDM. IEEE Photonics Technology Letters, Vol.17, No.2, pp. 504-506.

Ellis, A.D., Tomkos, I., Mishra, A.K., Zhao, J., Ibrahim, S.K., Frascella, P. \& Gunning, F.C.G. (2009a). Adaptive Modulation Schemes. Digest of LEOS Summer Topical Meetings (2009), TuD3.2.

Ellis, A.D., Gunning, F.C.G. \& Healy, T.C. (2009b). Communication Systems. US patent filed Oct 2006, published Mar 2009, US 2009/0074416 A1.

Ellis, A.D., Zhao, J. \& Cotter, D. (2010). Approaching the Non-Linear Shannon Limit. IEEE Journal of Lightwave Technology, Vol.28, No.4, pp.423-433.

Essiambre, R.-J., Winzer, P.J. \& Grosz, D.F. (2006). Impact of DCF properties on system design. Journal of Optical Fiber Communications Reports 3, pp.221-291.

Essiambre, R.-J., Kramer, G., Winzer, P.J., Foschini, G.J. \& Goebel, B. (2010). Capacity Limits of Optical Fiber Networks. IEEE Journal of Lightwave Technology, Vol.28, No.4, pp.662-701, Feb 2010.

Feced, R., Rickard, R. \& Richard, E. (2005). Reference Phase and Amplitude Estimation for Coherent Optical Receiver. US Patent 2005/0180760, filed Feb 2004, published Aug 2005.

Frascella, P., Mac Suibhne, N., Gunning, F.C.G., Ibrahim, S.K., Gunning, P. \& Ellis, A.D. (2010c). Unrepeatered field transmission of 2 Tbit/s multi-banded coherent WDM over 124km of installed SMF. Optics Express, Vol.18, No.24, pp. 24745-24752 (Nov 2010). 
Frascella, P., Gunning, F.C.G., Ibrahim, S.K., Gunning, P. \& Ellis, A.D. (2010b). PMD tolerance of $288 \mathrm{Gbit} / \mathrm{s}$ Coherent WDM and transmission over unrepeatered 124 $\mathrm{km}$ of field-installed single mode optical fiber. Optics Express, Vol.18, No.13, pp. 13908-13914, June 2010.

Frascella, P., Ibrahim, S.K., Gunning, F.C.G., Gunning, P. \& Ellis, A.D. (2010a). Transmission of a 288Gbit/s Ethernet Superchannel over $124 \mathrm{~km}$ un-repeatered field-installed SMF. Optical Fiber Communication Conference (Mar 2010), OThD2.

Gavioli, G., Torrengo, E., Bosco, G., Carena, A., Curri, V., Miot, V., Poggiolini, P., Belmonte, M., Guglierame, A., Brinciotti, A., La Porta, A., Forghieri, F., Muzio, C., Osnago, G., Piciaccia, S., Lezzi, C., Molle, L. \& Freund, R. (2009). 100 Gb/s WDM NRZ-PMQPSK Long-Haul Transmission Experiment over Installed Fiber Probing NonLinear Reach with and without DCUs. European Conference on Optical Communications (Sep 2009), Tu3.4.2.

Goldfarb, G., Li, G. \& Taylor, M.G. (2007). Orthogonal Wavelength-Division Multiplexing using Coherent Detection. IEEE Photonics Technology Letters, Vol.19, No.24, pp. 2015-2017.

Gunning, F.C.G., Healy, T., Manning, R.J. \& Ellis, A.D. (2005). Multi-banded Coherent WDM Transmission. European Conference on Optical Communications, Proceedings Vol.6, Paper Th4.2.6 (Sep 2005).

Headley, C. \& Agrawal, G.P., (2005). Raman Amplification in Fiber Optical Communications Systems. Elsevier Academic Press, ISBN: 0-12-044506-9.

Healy, T., Gunning, F.C.G. \& Ellis, A.D., (2006). Phase Stabilisation of Coherent WDM Modulator Array. Optical Fiber Communication Conference (Mar 2006), OTuI5.

Healy, T., Ellis, A.D., Gunning, F.C.G., Cuenot, B. \& Rukosueva, M. (2006). 1 b/s/Hz Coherent WDM Transmission over $112 \mathrm{~km}$ of Dispersion Managed Optical Fiber. Optical Fiber Communication Conference (Mar 2006), JThB10.

Healy, T., Gunning, F.C.G., Ellis, A.D. \& J.D. Bull (2007). Multi-wavelength source using low drive-voltage amplitude modulators for optical communications. Optics Express, Vol.16, No.6, pp.2981-2986, March 2007.

Healy, T., Gunning, F.C.G., Pincemin, E., Cuenot, B. \& Ellis, A.D. (2007). 1,200 km SMF (100 km spans) 280 Gbit/s Coherent WDM Transmission using Hybrid Raman/EDFA Amplification. European Conference on Optical Communications 2007, Mo.1.3.5.

Hillerkuss, D., Schmogrow, R., Schellinger, T., Jordan, M., Winter, M., Huber, G., Vallaitis, T., Bonk, R., Kleinow, P., Frey, F., Roeger, M., Koenig, S., Ludwig, A., Marculescu, A., Li, J., Hoh, M., Dreschmann, M., Meyer, J., Ben Ezra, S., Narkiss, N., Nebendahl, B., Parmigiani, F., Petropoulos, P., Resan, B., Oehler, A., Weingarten, K., Ellermeyer, T., Lutz, J., Moeller, M., Huebner, M., Becker, J., Koos, C., Freude, W. \& Leuthold, J. (2011). 26 Tbit s$^{-1}$ line-rate super-channel transmission utilizing alloptical fast Fourier transform processing. Nature Photonics, Vol.74, pp.1-8, DOI:10.1038, May 2011.

Huang, Y.-K., Qian, D., Saperstein, R.E., Ji, P.N., Cvijetic, N., Xu, L. \& Wang, T. (2009). DualPolarization 2x2 IFFT/FFT Optical Signal Processing for 100-Gb/s QPSK-PDM AllOptical OFDM. Optical Fiber Communication Conference (Mar 2009), OTuM4.

Ibrahim, S.K., Zhao, J., Gunning, F.C.G., Frascella, P., Peters, F.H. \& Ellis, A.D. Towards a Practical Implementation of Coherent WDM: Analytical, Numerical, and Experimental Studies. IEEE Photonics Journal, Vol.2, No.5, Oct 2010. 
Ito, S. \& Yokoyama, S. (1967). Phase-modulated frequency division multiplex system. US Patent 3,349,182, filed June 1964, published Oct 1967.

Jansen, S.L. et al. (2008a). OSA-JON, Vol.7, pp. 173-182, 2008.

Jansen, S.L., Morita, I. \& Tanaka, H. (2008b). 10 x 121.9-Gb/s PDM-OFDM transmission with 2-b/s/Hz spectral efficiency over $1000 \mathrm{~km}$ of SMF. Optical Fiber Communication Conference (Feb 2008), PDP2.

Jansen, S.L., Morita, I., Takeda, N. \& Tanaka, H. (2007). 20-Gb/s OFDM Transmission over 4,160-km SSMF Enabled by RF-Pilot Tone Phase Noise Compensation. Proceedings of Optical Fiber Communication (OFC) Conference 2007, PDP 15.

Kaminow, I.P., Li, T. \& Willner, A.E., (2008). Optical Fiber Telecommunications V A: Components and Subsystems, Elsevier 2008.

Kikuchi, K. (1990). Generalized formula for optical amplifier noise and its application to erbium-doped fibre amplifiers. Electronics Letters, Vol.26, No.22, p.1851 (1990).

Lam, C.F., Liu, H., Koley, B., Zhao, X., Kamalov, V. \& Gill, V. (2010). Fiber Optic Communication Technologies: What's Needed for Datacenter Network Operations. IEEE Communications Magazine, Vol.48, No.7 (2010).

Lee D. (2011). Scaling Networks in Large Data Centers. Optical Fiber Communication Conference (Mar 2011), OWU1.

Liu, X., Buchali, F. \& Tkach, R.W. (2009). Improving the nonlinear tolerance of polarizationdivision-multiplexed CO-OFDM in long-haul fiber transmission. IEEE Journal of Lightwave Technology, Vol.27, No.16, pp. 3632-3640, Aug. 2009.

Lowery, A.J., Du L. \& Armstrong, J. (2006). Orthogonal Frequency Division Multiplexing for Adaptive Dispersion Compensation in Long Haul WDM Systems. Optical Fiber Communication Conference (2006) PDP39.

Lowery, A.J. (2010). Design of arrayed-waveguide grating routers for use as optical OFDM demultiplexers. Optics Express, Vol.18, No.13, pp. 14129-14143 (Jun 2010).

Mitra, P.P. \& Stark, J.B. (2001). Nonlinear limits to the information capacity of optical fibre communications. Nature, Vol.411, pp. 1027-1030, 2001.

Mosier, R.R. \& Clabaugh, R.G. (1958). Kineplex, a bandwidth efficient binary transmission system. AIEE Transactions, Vol.76, pp. 723-728 (Jan 1958).

Nissov, M., Rotwitt, K., Kidorf, H.D. \&Ma, M.X. (1999). Rayleigh crosstalk in long cascades of distributed unsaturated Raman amplifiers. Electronics Letters, Vol.35, pp. 997-998.

Pizzinat, A., Santagiustina, M. \& Schivo, C., (2003). Impact of Hybrid EDFA-Distributed Raman Amplification on a $4 \times 40-G b / s$ WDM Optical Cmmunication System. IEEE Photonics Technology Letters, Vol.15, No.2, pp. 341-343.

Poole, S., Frisken, S., Roelens, M. \& Cameron C. (2011). Bandwidth-flexible ROADMs as Network Elements. Proceedings of Optical Fiber Communication (OFC) Conference 2011, OTuE1.

Proakis, J.G. \& Salehi, M., (2008). Digital Communications. $5^{\text {th }}$ edition, Mc Graw Hill, New York, 2008.

Qian, D., Huang, M.-F., Ip, E., Huang, Y.-K., Shao, Y., Hu, J., \& Wang, T. (2011). 101.7-Tb/s $(370 \times 294-\mathrm{Gb} / \mathrm{s})$ PDM-128QAM-OFDM transmission over $3 \times 55-\mathrm{km}$ SSMF using Pilot-based phase noise mitigation. Optical Fiber Communication Conference (2011), PDPB5.

Reuters, (2010a) “World Bank Sees African Economies Rebounding in 2010," March 18, 2010. Reuters, (2010b) “Davos Special Report: Africa Rising,” January 26, 2010. 
Roberts, K. (2011). Digital Signal Processing for Coherent Optical Communications: Current State of the Art and Future Challenges. OSA Annual Meeting, Advanced Photonics Congress, 12-15 June 2011, Toronto, Canada, SPWC1.

Rodrigues, M.R.D. \& Darwazeh, I (2002). Fast OFDM: A proposal for doubling the data rate of OFDM schemes. Proceedings of IEEE/IEE International Conference on Telecommunications (ICT 2002), Beijing, China. (pp. 484 - 487).

Sanjoh, H., Yamada, E. \& Yoshikuni, Y. (2002). Optical orthogonal frequency division multiplexing using frequency/time domain filtering for high spectral efficiency up to 1 bit/s/Hz. Optical Fiber Communication Conference (2002), ThD1.

Sano, A., Yamada, E., Masuda, H., Yamazaki, E., Kobayashi, T., Yoshida, E., Miyamoto, Y., Kudo, R., Ishihara, K. \& Takatori, Y. (2009). No-Guard-Interval Coherent Optical OFDM for 100-Gb/s Long-Haul WDM Transmission. IEEE Journal of Lightwave Technology, Vol.27, No.16, Aug 2009.

Sano, A., Masuda, H., Kobayashi, T., Yamada, E., Miyamoto, Y., Hibino, Y., Ishihara, K., Takatori, Y., Hagimoto, K., Yamada, T. \& Sakamaki, Y. (2007). $30 \times 100$ Gb/s alloptical OFDM transmission over $1300 \mathrm{~km}$ SMF with 10 ROADM nodes. European Conference on Optical Communications (Sep 2007), PD1.7.

Schmogrow R. et al. (2011). $101.5 \mathrm{Gbit} / \mathrm{s}$ Real-time OFDM transmitter with 16QAM modulated subcarriers. Optical Fiber Communication Conference (Mar 2011), OWE5.

Shieh, W. \& Authaudage, C. (2006). Coherent optical orthogonal frequency division multiplexing. Electronics Letters, Vol.42, No.10, p. 587.

Shieh, W., Yang, Q. \& Ma, Y. (2008). 107 Gb/s coherent optical OFDM transmission over 1000-km SSMF using orthogonal band multiplexing. Optics Express, Vol.16, No.9, pp. 6378-6386.

Stolen, R.H., Ippen, E.P. \& Tynes, A.R., (1972). Raman Oscillation in Glass Optical Waveguides. Applied Physics Letters 20 (2), pp. 62-64, 1972.

Takara, H., Kozicki, B., Sone, Y., Tanaka, T., Watanabe, A., Hirano, A., Yonenaga, K. \& Jinno, M. (2010). Distance-Adaptive Super-Wavelength Routing in Elastic Optical Path Network (SLICE) with Optical OFDM. Proceedings of European Conference on Optical Communication (ECOC), Sep 2010, Paper We.8.D.2.

Thiagarajan, S., Frankel, M. \& Boertjes, D. (2011). Spectrum Efficient Super-Channels in Dynamic Flexible Grid Networks - A Blocking Analysis. Proceedings of Optical Fiber Communication (OFC) Conference 2011, OTuI6.

Walker, G.R., Spirit, D.M., Williams, D.L. \& Davey, S.T. (1991). Noise performance of distributed fiber amplifiers. Electronics Letters, Vol.27, No.15, p.1390 (1991).

Weinstein, S. \& Ebert, P. (1971). Data transmission by frequency division multiplexing the discrete Fourier transform. IEEE Transactions on Communication Technology, Vol.COM-19, pp. 628-634, October 1971.

www.infonetics.com (2011). ROADM WSS component market on pace for $20 \%$ annual growth through 2015. available at www.infonetics.com, May 2011.

Xia, T.J., Wellbrock, G.A., Huang, Y.-K., Ip, E., Huang, M.-F., Shao, Y., Wang, T., Aono, Y., Tajima, T., Murakami, S. \& Cvijetic, M. (2011). Field experiment with mixed linerate transmission $(112-\mathrm{Gb} / \mathrm{s}, 450-\mathrm{Gb} / \mathrm{s}$, and $1.15-\mathrm{Tb} / \mathrm{s})$ over $3,560 \mathrm{~km}$ of installed fiber using filterless coherent receiver and EDFAs only. Optical Fiber Communication Conference (2011), PDPA3. 
Yamamoto, Y. \& Inoue, K. (2003). Noise in amplifiers. IEEE Journal of Lightwave Technology, Vol.21, No.11.

Yamamoto, S., Yonenaga, K., Sahara, A., Inuzuka, F. \& Takada, A. (2010). Achievement of sub-channel frequency spacing less than symbol rate and improvement of dispersion tolerance in optical OFDM transmission. IEEE Journal of Lightwave Technology, Vol.28, pp.157-163 (2010).

Yonenaga, K., Inuzuka, F., Yamamoto, S., Takara, H., Kozichi, B., Yoshimatsu, T., Takada, A. \& Jinno, M. (2009). Bit-rate-flexible all-optical OFDM transceiver using variable multi-carrier source and DQPSK/DPSK mixed multiplexing. Optical Fiber Communication Conference (Mar 2009), pp. 1-3, OWM1.

Zhao, J. \& Ellis, A.D., (2010). A Novel Optical Fast OFDM with Reduced Channel Spacing Equal to Half of the Symbol Rate Per Carrier. Optical Fiber Communication Conference (Mar 2010), OMR1.

Zhao, J. \& Ellis, A.D. (2011). Electronic Impairment Mitigation in Optically Multiplexed Multicarrier Systems. IEEE Journal of Lightwave Technology, Vol.29, No.3, pp.278290, (2011).

Zhu, B., Taunay, T.F., Fishteyn, M., Liu, X., Chadrasekhar, S., Yan, M.F., Fini, J.M, Monberg, E.M., Dimarcello, F.V., Abedin, K., Wisk, P.W., Peckham, D.W. \& Dziedzic, P. (2011). Space-, Wavelength-, Polarisation-Division Multiplexed transmission of 56$\mathrm{Tb} / \mathrm{s}$ over a 76.8-km seven-core fiber. Optical Fiber Communication Conference (Mar 2011), PDPB7.

Zimmerman, M.S. \& Kirsch, A.L. (1967). The AN/GSC-10 (KATHRYN) Variable Rate Data Modem for HF Radio. IEEE Transactions on Communication Technology, Vol.COM-15, No.2, pp. 197-204 (1967). 


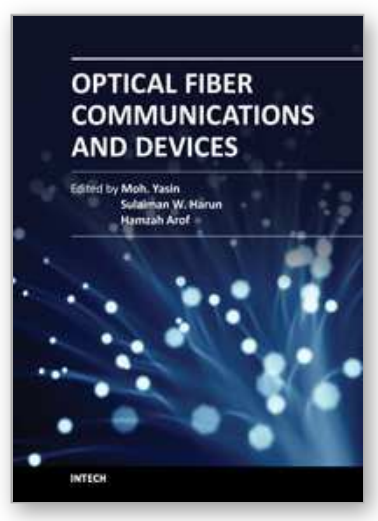

\author{
Optical Fiber Communications and Devices \\ Edited by Dr Moh. Yasin
}

ISBN 978-953-307-954-7

Hard cover, 380 pages

Publisher InTech

Published online 01, February, 2012

Published in print edition February, 2012

This book is a collection of works dealing with the important technologies and mathematical concepts behind today's optical fiber communications and devices. It features 17 selected topics such as architecture and topologies of optical networks, secure optical communication, PONs, LANs, and WANs and thus provides an overall view of current research trends and technology on these topics. The book compiles worldwide contributions from many prominent universities and research centers, bringing together leading academics and scientists in the field of photonics and optical communications. This compendium is an invaluable reference edited by three scientists with a wide knowledge of the field and the community. Researchers and practitioners working in photonics and optical communications will find this book a valuable resource.

\title{
How to reference
}

In order to correctly reference this scholarly work, feel free to copy and paste the following:

Paola Frascella and Andrew D. Ellis (2012). 2 Terabit Transmission over Installed SMF with Direct Detection Coherent WDM, Optical Fiber Communications and Devices, Dr Moh. Yasin (Ed.), ISBN: 978-953-307-954-7, InTech, Available from: http://www.intechopen.com/books/optical-fiber-communications-and-devices/2-terabittransmission-over-installed-smf-with-direct-detection-coherent-wdm

\section{INTECH}

open science | open minds

\section{InTech Europe}

University Campus STeP Ri

Slavka Krautzeka 83/A

51000 Rijeka, Croatia

Phone: +385 (51) 770447

Fax: +385 (51) 686166

www.intechopen.com

\section{InTech China}

Unit 405, Office Block, Hotel Equatorial Shanghai

No.65, Yan An Road (West), Shanghai, 200040, China

中国上海市延安西路65号上海国际贵都大饭店办公楼 405 单元

Phone: +86-21-62489820

Fax: $+86-21-62489821$ 
(C) 2012 The Author(s). Licensee IntechOpen. This is an open access article distributed under the terms of the Creative Commons Attribution 3.0 License, which permits unrestricted use, distribution, and reproduction in any medium, provided the original work is properly cited. 